\title{
The direct response of Drosophila melanogaster to selection on knockdown temperature
}

\author{
GEORGE W. GILCHRIST* \& RAYMOND B. HUEY \\ Department of Zoology, Box 351800, University of Washington, Seattle, WA 98195-1800, U.S.A.
}

\begin{abstract}
We selected on knockdown temperature, the upper temperature at which insects lose the ability to cling to an inclined surface, in replicate populations of Drosophila melanogaster for 32 generations (46 generations of rearing). Knockdown temperature $\left(T_{\mathrm{kd}}\right)$ was initially bimodally distributed in both control and selected lines, and a similar pattern was found in several populations surveyed from two other continents. Within 20 generations of selection, the Up-selected lines (top 25\% each generation) had lost the lower mode and the Low-selected lines (selected to fall out at $\approx 37^{\circ} \mathrm{C}$ ) had largely lost the upper mode. The realized heritability of $T_{\mathrm{kd}}$ computed over the first 10 selection episodes was $\approx 0.12$ in the Up-selected and $\approx 0.19$ in the Low-selected lines. Realized heritability rose dramatically in the Low-selected lines over the first 20 generations of selection. The two modes, plus this rise in heritability, suggest that knockdown temperature is the product of one or two genes of large effect. The global polymorphism for knockdown temperature, coupled with the ease of selective removal of either mode, suggests that genetic variation for knockdown temperature may be maintained by natural selection.
\end{abstract}

Keywords: artificial selection, Drosophila melanogaster, knockdown, performance, temperature.

\section{Introduction}

Daily, seasonal, and spatial variation in environmental temperatures can have profound effects on the patterns of daily activity for ectotherms (Huey \& Pianka, 1977; Clarke, 1996). Large ectotherms have well-developed capacities for behavioural temperature regulation and can thus minimize the impact of these environmental effects (Stevenson, 1985). However, small insects such as Drosophila melanogaster are essentially isothermal with their microenvironment (Stevenson, 1985) and can control body temperatures only by moving to favourable habitats (Casey \& Hegel, 1981). Selection on these animals may favour evolutionary shifts in thermal sensitivity of physiology along environmental thermal gradients. The common observation that temperature sensitivity in Drosophila varies geographically (Levins, 1969; Coyne et al., 1983; David, 1988; Hoffmann \& Parsons, 1991) suggests that selection on thermal sensitivity is important in nature and that genetic

*Correspondence and present address: Department of Biology, Box 5805, Clarkson University, Potsdam, NY 13699-5805, U.S.A. E-mail: gilchrgw@clarkson.edu variation is available for at least some components of thermal physiology.

One way to examine the standing genetic potential for rapid evolution of temperature sensitivity is through selection experiments. Previous studies with Drosophila and other ectotherms have used either laboratory natural selection in different thermal environments (Stephanou \& Alahiotis, 1983; Cavicchi et al., 1985; Bennett et al., 1992; Partridge et al., 1995) or artificial selection on either heat or cold tolerance (Kindred, 1965; White et al., 1970; Morrison \& Milkman, 1978; Pennycuik, 1979; Stephanou \& Alahiotis, 1983; Quintana \& Prevosti, 1990; McColl et al., 1996; Hoffmann et al., 1997). Artificial selection for resistance to high temperatures in Drosophila is usually carried out through family selection because high temperature exposure often sterilizes the surviving flies (Morrison \& Milkman, 1978; Quintana \& Prevosti, 1990).

Here we present the results of artificial selection on knockdown temperature $\left(T_{\mathrm{kd}}\right)$, a convenient index of high-temperature sensitivity (Huey et al., 1992). $T_{\mathrm{kd}}$ is that temperature at which the fly loses its ability to grip a textured, inclined surface inside a Weber column (Weber, 1988; Weber \& Diggins, 1990). The measurement is similar to the 'critical thermal maximum' (loss of 
righting response) commonly used to study heat sensitivity in diverse ectotherms. Knockdown temperature is correlated with the ability to locomote at high temperatures (Gilchrist, unpubl. data). It can be quickly measured on hundreds of individuals with no apparent increase in mortality or infertility, so that family selection is unnecessary. A preliminary experiment (Huey et al., 1992) suggested that $T_{\mathrm{kd}}$ would exhibit a rapid response to selection.

We selected on a recently collected population of Drosophila melanogaster to explore the magnitude of genetic variation in $T_{\mathrm{kd}}$. We initially set up six lines selected for high $T_{\mathrm{kd}}$ and six control lines; we selected the top $25 \%$ of the flies in the Up-selected lines, and a random $25 \%$ from the Control lines. We initially chose not to select for low $T_{\mathrm{kd}}$ (e.g. the bottom $25 \%$ ) because we were concerned that down selection could select for inferior flies or for flies that simply 'let go' when dropped into the column. For example, D. melanogaster with low fitness because of mutation accumulation often fell through the Weber column without ever getting a grip (Huey, unpublished observation).

Within the first few generations of selection, it became apparent that $T_{\mathrm{kd}}$ was bimodally distributed. Although the small selection of $T_{\mathrm{kd}}$ histograms in Fig. 1 show some lines that might be interpreted as simply skewed to the left, in generation after generation most of the control lines showed two peaks separated by a valley. Furthermore, the estimates of the means and standard deviations of the peaks were remarkably consistent (Fig. 2; see Results for details). Beginning at generation five, we selected flies from within the lower mode ('Low-selected') as a surrogate for down-selecting by truncation in a similar manner to the Up-selected lines. We contrast our results with a recent study of selection on knockdown time (McColl et al., 1996; Hoffmann et al., 1997).

\section{Materials and methods}

\section{Establishment and maintenance of lines}

Drosophila melanogaster used in this experiment originated from a large population $(\approx 1000$ isofemale lines, courtesy of L. Harshmann \& M. Turelli) collected from Escalon, CA in May 1991. This stock was maintained at the University of California, Davis for almost 1 year $\left(\approx 22^{\circ} \mathrm{C}, 13 \mathrm{~L}: 11 \mathrm{D}\right.$ cycle). In April 1992, we received a sample $(\approx 1000$ flies $)$ and began rearing the flies at a controlled density $(\approx 50$ eggs/vial; cornmeal, molasses, yeast, agar, tegosept) before transfer to population cages of 2000-3000 adults with discrete two-week generations at $25^{\circ} \mathrm{C}(12 \mathrm{~L}: 12 \mathrm{D})$.

The six Control lines and the six Up-selected lines were each established with six half-pint bottles, with each bottle stocked with $\approx 100$ flies haphazardly selected from the population cages on 15 November 1993. The eggs for the initial generation of selection were collected on the following day. For each line, $\approx 50$ eggs were placed in each of 28 vials and reared to adulthood at $25^{\circ} \mathrm{C}$ (12 L:12D). Eleven days later, the eclosed flies were transferred to fresh vials with a pinch of dry yeast.

\section{Measuring and selecting on knockdown temperature}

The first generation of selection occurred on 29 and 30 November 1993. Six haphazardly chosen lines $(\approx 1000$ flies, estimated by volume) were run on each day. Basic procedures for measuring knockdown temperature are detailed in Huey et al. (1992). In brief, adult flies are tossed into the top of a Weber column $(120 \times 7.5 \mathrm{~cm})$ with internal baffles (Weber, 1988), that is surrounded by a temperature-controlled water jacket. Water is continuously circulated through the jacket from a fivegallon water bath with a Haake E30 heater/pump and a Haake W40 immersion cooler. The temperature of the water is heated from 30 to $50^{\circ} \mathrm{C}$ over about $20 \mathrm{~min}$. The air temperature within the column lags about $2-3^{\circ} \mathrm{C}$ behind the water temperature, but is relatively uniform $\left( \pm 0.2^{\circ} \mathrm{C}\right)$ between any two points within the column. As the column heats, the flies eventually lose their grip on the walls or baffles and fall through an opening in the bottom. Column temperatures are monitored, and the flies are fractionated in $0.5^{\circ} \mathrm{C}$ intervals, and later sexed and counted.

We selected for high knockdown temperature (Upselected lines) by retaining the top $25 \%$ of the flies $(\approx 250$ individuals) from a particular run. Males and females were selected separately. In each Control line, $25 \%$ of all males and females were chosen haphazardly. The 'selected' flies were then divided among six half-pint bottles containing $30 \mathrm{~mL}$ of medium and a sprinkle of yeast; they then were incubated at $25^{\circ} \mathrm{C}$.

Selection on the Low lines (selected from the lower mode of the $T_{\mathrm{kd}}$ ) began in generation 5 using a targeted selection protocol rather than the truncation selection used for the Up-selected lines. In generation 3, we set up a base stock by pooling $\approx 300$ eggs from each of the six Control lines. At generation 4 of selection, we set up three lines each with $\approx 125$ males and 125 females from this base stock divided among six bottles per line. These animals were reared and eggs collected as for the Upselected and Control lines. Beginning at generation 5, the three Low-selected lines were run through the column; we selected the $25 \%$ of the population centred around $37^{\circ} \mathrm{C}$ (in early generations, the selected flies were collected at $36.0-38.0^{\circ} \mathrm{C}$; in later generations, this window was narrowed to $36.5-37.5^{\circ} \mathrm{C}$ ). For generations 

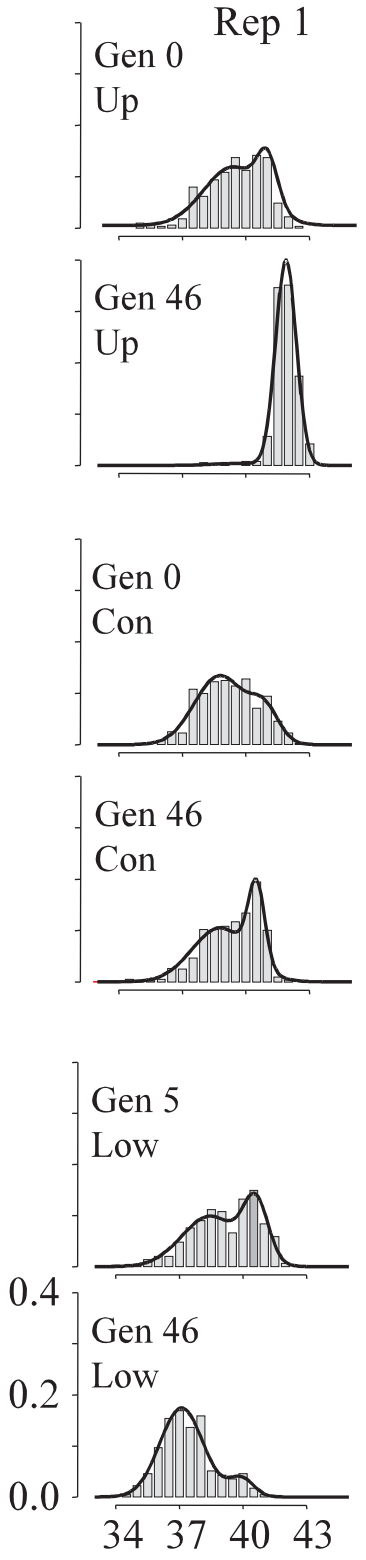
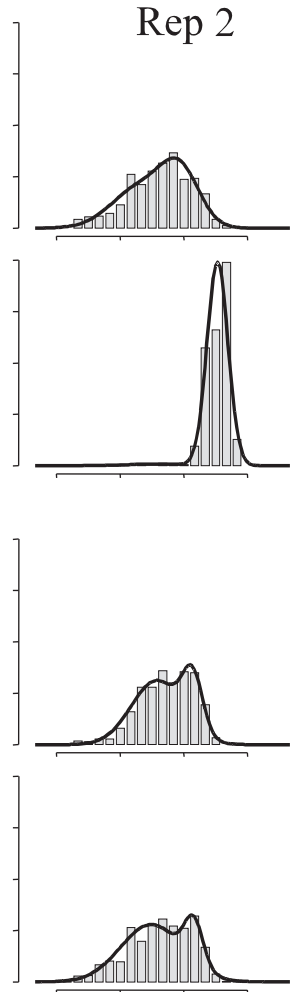

Fig. 1 Histograms (proportional) of $T_{\mathrm{kd}}$ for generations 0 and 46 for three Up-selected and Control lines, and the three Low-selected lines of Drosophila melanogaster. The lines show the maximum likelihood fit for a bimodal distribution (fitted parameters in Appendices 1 and 2). Female distributions are shown; the distributions of males are similar.
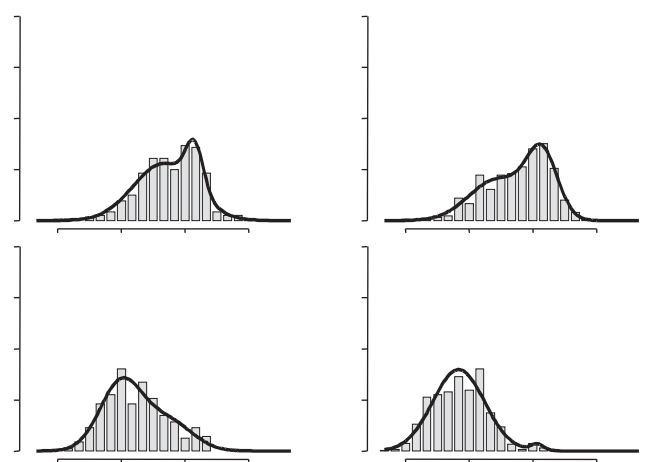
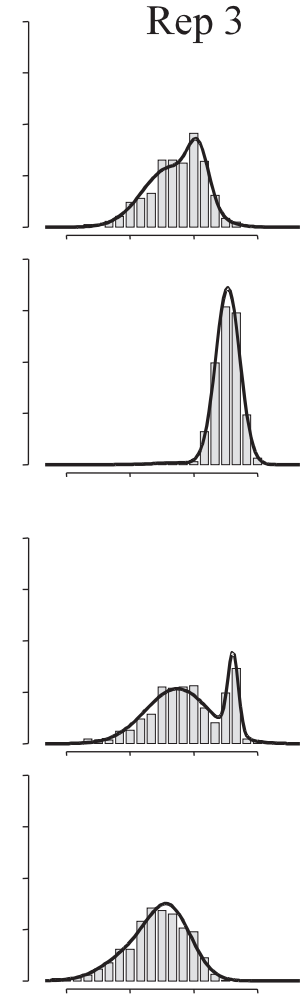

\section{$T_{\text {kd }}\left({ }^{\circ} \mathrm{C}\right)$}

6 and 7, we selected the Low-selected flies but did not count and record every fraction because of time constraints. By convention, we will use the same numbering scheme to refer to the generations in all three selection treatments.

In all lines, the selected males and females were held together for one week before collecting eggs for the next generation. This lag for remating meant that we could run fewer generations per unit time, but had the advantage of increasing the strength of selection. Drosophila melanogaster shows a high degree of last-male sperm precedence, so that at least $85 \%$ of the offspring produced by a doubly mated female are sired by the second male (Gromko et al., 1984). Test crosses between our stocks and flies homozygous for a dominant eye colour mutant (brown) showed that over $90 \%$ of females remated within one week, with high levels of last-male sperm precedence. [Note: the alternative of collecting and selecting virgins was not practicable.]

Eggs were collected and transferred to vials $(\approx 50$ eggs per vial) that were then held at $25^{\circ} \mathrm{C}(12 \mathrm{~L}: 12 \mathrm{D})$ until hatching. After eclosion, adults were transferred to fresh media with yeast $2-3$ days prior to the next round of selection.

(C) The Genetical Society of Great Britain, Heredity, 83, 15-29. 

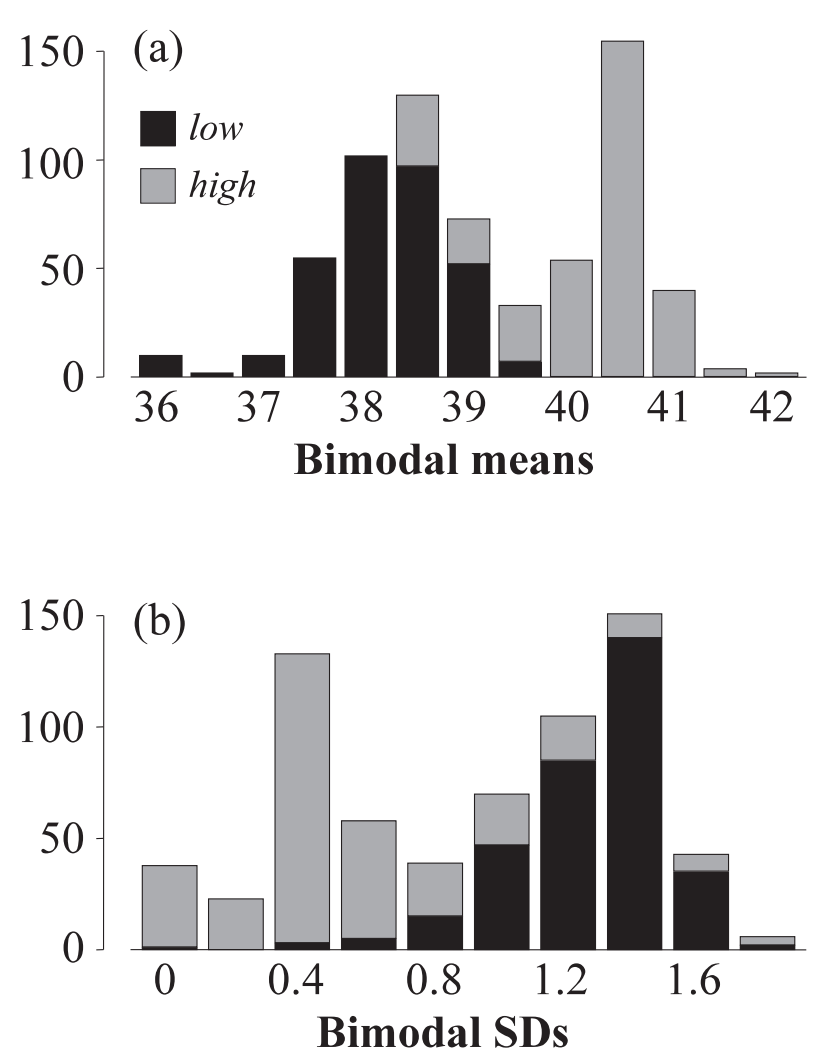

Fig. 2 Distribution of parameter estimates for the bimodal model (Controls only). (a) The estimated means $M_{\text {low }}$ (black) and $M_{\text {high (grey) over all generations. (b) The estimated }}$ standard deviations $S_{\text {low }}$ (black) and $S_{\text {high }}$ (grey) over all generations.

Here we report on the response to selection to generation 46. Selection was skipped in generations 2, $12,17,28,30,32,34,35,37,38,40,41,43,44$, and 45 . In these generations, $\approx 125$ adults of each sex (haphazardly selected) were used to found the next generation.

\section{Statistics}

The parameters of the unimodal and bimodal (mixture of two normal) distributions were estimated through maximum likelihood (Lynch \& Walsh, 1998). We programmed s-PLUs (StatSci, 1993) to estimate the two parameters of a unimodal normal distribution $\left(\sim \mathrm{N}\left(M_{\mathrm{u}}, S_{\mathrm{u}}\right)\right.$, where $\mathrm{N}(\bar{x}, \sigma)$ indicates the normal distribution probability function, $M_{\mathrm{u}}=$ mean $\bar{x}$, and $S_{\mathrm{u}}=$ standard deviation $\sigma$ ) and the five parameters of a bimodal normal mixture distribution $\left(\sim P_{\text {low }} \times \mathrm{N}\left(M_{\text {low }}, S_{\text {low }}\right)+\left(1-P_{\text {low }}\right) \times \mathrm{N}\left(M_{\text {high }}, S_{\text {high }}\right)\right.$, where $M_{\text {low }}$ and $M_{\text {high }}=$ means of the low and high modes, $S_{\text {low }}$ and $S_{\text {high }}=$ standard deviations of low and high modes, and $P_{\text {low }}=$ proportion of the population falling under the low mode). The hypothesis that the bimodal distribution provided a better description of the data was tested using a log-likelihood ratio test for each line in each generation (see Results). The $G$-statistic follows a chi-squared distribution, with the appropriate degrees of freedom being the difference in the number of parameters in each model (d.f. $=3$ in all tests). Similar results are obtained with other tests, such as the AIC; however, the log-likelihood test is more conservative.

Occasionally several flies fell out of the Weber column at an unusually low temperature, creating a spurious peak in the maximum likelihood estimation of bimodal distribution parameters. In these cases, the parameter estimates for $M_{\text {high }}$ and $S_{\text {high }}$ were actually the estimates of $M_{\text {low }}$ and $S_{\text {low }}$. In the Low-selected lines where this was most commonly observed, the erroneous parameter estimates were identified by inspection and re-estimated prior to final analysis. A second potential problem is that a five-parameter model will give a better fit than a two-parameter model to almost any data set that departs from normality. One could argue that the distribution of $T_{\mathrm{kd}}$ is not really bimodal, but simply skewed or platykurtic. Visual inspection of the data (e.g. Figure 1) does not support this contention; we consistently find two peaks with predictable means and variances in generation after generation. Transformation fails to remove the bimodality. Additional statistical procedures will be described in the Results.

\section{Heritability estimates}

The realized heritability of knockdown temperature was estimated by regressing the response to selection against the selection differential over the first 10 generations of selection (Falconer, 1989). The replicated lines were treated as fixed factors in the analysis, with heterogeneity within a selection treatment determined by a comparison of slopes. Because some small unknown portion of the Up- and Low-selected lines in each generation are sired by unselected males (see above), the selection differentials represent maximum rather than realized values, resulting in an underestimate of the true heritability (Falconer, 1989). For the heritabilities of the bimodal parameters, the selection differential for the low mean was computed as the difference between the mean $T_{\mathrm{kd}}$ of the selected flies and $M_{\mathrm{low}}$ of the total population. The selection differential for the high mean was computed as the difference between the mean $T_{\mathrm{kd}}$ of the selected flies and $M_{\text {high }}$ of the total population.

To see how the heritability changed over the course of the experiment, we regressed the response to selection against the selection differential for each line over a sliding window of 10 selection episodes (regressions ending with generations $11-46$ for the Up-selected lines and generations 16-46 for the Low-selected lines). 


\section{Relaxed selection lines}

Relaxation of selection is often accompanied by a regression of the selected lines towards the controls, reflecting reduced fitness of selected lines (Clayton et al., 1957). In generation 23 , we collected $\approx 250$ flies from three Up-selected lines and removed them from selection. In each generation, $25 \%$ of 1000 haphazardly chosen flies were collected for oviposition. $T_{\mathrm{kd}}$ was measured on these relaxed selection lines in generation 46 .

\section{Results}

\section{The bimodality of $\mathrm{T}_{k d}$}

The distributions of knockdown temperature for males (the distributions for females are similar) at the start of selection (generation 0 for the Up and Control lines, generation 5 for the Low lines) and at generation 46 (after 32 generations of selection) are shown in Fig. 1. The bimodality of the $T_{\mathrm{kd}}$ distributions was visually apparent in most of the lines at the start of selection, and was still evident in the Controls at generation 46. This bimodality is not an artifact, as the two modes appeared consistently in the Control lines in nearly every generation.

A summary of the mean parameter estimates for the unimodal and bimodal distributions is provided in Table 1. Parameter estimates for all lines at the start of the experiment and at generation 46 are tabulated in Appendices 1 and 2. We used likelihood ratio tests to compare the goodness-of-fit to the unimodal and bimodal distributions (see Materials and methods).
A bimodal normal mixture distribution gave a better fit (likelihood ratio test, $P<0.05$ ) than a unimodal distribution in $87.8 \%$ of the Control runs, $98.2 \%$ of the Up runs and $64.1 \%$ of the Low runs. The two modes at the start of selection were at about $38.5^{\circ} \mathrm{C}$ and $40.5^{\circ} \mathrm{C}$, with about $60 \%$ of the flies falling under the lower mode (Table 1).

The means and standard deviations of the two modes were consistent throughout the course of the experiment in the Controls, as shown by the histograms in Fig. 2. The low mean was usually near $38.0-38.5^{\circ} \mathrm{C}$, and the high mean near $40.5^{\circ} \mathrm{C}$. Note that in several cases, the mean of the upper mode was estimated at $\approx 38.5^{\circ} \mathrm{C}$ (Fig. 2a); these correspond to cases where the maximum likelihood estimate of $M_{\text {high }}$ actually corresponds to the expectation for $M_{\text {low }}$. These are the same observations in which the estimates of $S_{\text {high }}$ are large and similar to the expectation for $S_{\text {low }}$ (Fig. 2b), indicating that the maximum likelihood routine has identified a spurious lower mode.

No evidence suggests that the bimodality is simply an artifact of mating or developmental status of the flies. First, both males and females have nearly identical bimodal distributions of $T_{\mathrm{kd}}$, suggesting that sex or mating status does not determine the bimodality. Males and females are held together 3-5 days prior to testing, so the proportion of virgin females must be extremely small; individual females collected after a $T_{\mathrm{kd}}$ assay virtually all lay viable eggs (Huey et al., 1992).

Knockdown temperature drops slowly as the flies age, but the differences are small. Because flies for each selection episode are collected on a single day but

Table 1 Parameter estimates for unimodal and bimodal distributions of knockdown temperature in Drosophila mealnogaster. The values shown are the mean (with SD in parentheses) of the replicate lines at the start of selection (generation 0 for the Controls and Up-selected lines, generation 5 for the Low-selected lines). Trt, selection treatment;

Gen, generation; Con, control

\begin{tabular}{|c|c|c|c|c|c|c|c|c|c|c|}
\hline \multirow[b]{2}{*}{ Trt } & \multirow[b]{2}{*}{ Sex } & \multirow[b]{2}{*}{ Gen } & \multirow[b]{2}{*}{$N$} & \multicolumn{2}{|c|}{ Unimodal } & \multicolumn{5}{|c|}{ Bimodal } \\
\hline & & & & $M_{\mathrm{u}}$ & $S_{\mathrm{u}}$ & $P_{\text {low }}$ & $M_{\text {low }}$ & $S_{\text {low }}$ & $M_{\text {high }}$ & $S_{\text {high }}$ \\
\hline \multirow[t]{4}{*}{ Con } & $\mathrm{F}$ & 0 & 6 & $39.66(0.865)$ & $1.59(0.566)$ & $0.69(0.250)$ & $38.96(0.655)$ & $1.54(0.653)$ & $41.20(1.692)$ & $0.50(0.375)$ \\
\hline & $\mathrm{F}$ & 46 & 6 & $38.68(0.526)$ & $1.42(0.103)$ & $0.72(0.192)$ & $38.21(0.600)$ & $1.35(0.104)$ & $40.04(0.655)$ & $0.52(0.402)$ \\
\hline & M & 0 & 6 & $39.37(0.850)$ & $1.66(0.624)$ & $0.71(0.067)$ & $38.64(0.401)$ & $1.39(0.264)$ & $41.09(1.715)$ & $0.46(0.121)$ \\
\hline & $\mathrm{M}$ & 46 & 6 & $38.87(0.493)$ & $1.44(0.101)$ & $0.59(0.152)$ & $38.11(0.543)$ & $1.36(0.073)$ & $40.01(0.582)$ & $0.57(0.286)$ \\
\hline \multirow[t]{4}{*}{ Up } & $\mathrm{F}$ & 0 & 6 & $39.21(0.389)$ & $1.36(0.093)$ & $0.45(0.361)$ & $37.83(1.604)$ & $1.13(0.358)$ & $39.96(0.782)$ & $0.79(0.342)$ \\
\hline & $\mathrm{F}$ & 46 & 6 & $41.73(0.195)$ & $0.63(0.048)$ & $0.02(0.006)$ & $39.49(0.504)$ & $1.38(0.187)$ & $41.78(0.204)$ & $0.49(0.064)$ \\
\hline & $\mathrm{M}$ & 0 & 6 & $38.95(0.438)$ & $1.39(0.080)$ & $0.68(0.164)$ & $38.35(0.178)$ & $1.28(0.055)$ & $40.25(0.157)$ & $0.44(0.248)$ \\
\hline & M & 46 & 6 & $41.62(0.251)$ & $0.65(0.120)$ & $0.04(0.027)$ & $39.34(0.489)$ & $1.12(0.624)$ & $41.70(0.219)$ & $0.44(0.051)$ \\
\hline \multirow[t]{4}{*}{ Low } & $\mathrm{F}$ & 0 & 3 & $39.52(0.132)$ & $1.46(0.075)$ & $0.62(0.117)$ & $38.83(0.355)$ & 1.32( & 40.64 & $0.77(0.185)$ \\
\hline & $\mathrm{F}$ & 46 & 3 & $36.90(0.250)$ & $1.22(0.161)$ & $0.99(0.009)$ & $36.87(0.273)$ & $1.18(0.195)$ & $40.21(0.580)$ & $0.17(0.340)$ \\
\hline & M & 0 & 3 & $39.25(0.080)$ & $1.49(0.069)$ & $0.68(0.160)$ & $38.60(0.436)$ & $1.38(0.069)$ & $40.50(0.111)$ & $0.57(0.188)$ \\
\hline & M & 46 & 3 & $37.23(0.726)$ & $1.37(0.114)$ & $0.85(0.192)$ & $36.87(0.399)$ & $1.08(0.147)$ & $39.78(0.622)$ & $0.68(0.506)$ \\
\hline
\end{tabular}

(C) The Genetical Society of Great Britain, Heredity, 83, 15-29. 
selected over two days, the effect of age differences can be assayed by comparing the $T_{\mathrm{kd}}$ parameters for flies selected on the first day and those selected on the second day of each generation (Table 2). Repeated measures ANOVAS for the lines over the entire experiment show a significant decrease between day 1 and day 2 in $M_{\mathrm{u}}$ for the Up-selected $\left(F_{1,372}=13.49, P<0.001\right)$ and Control lines $\left(F_{1,372}=14.07, P<0.001\right)$, in $M_{\text {high }}$ for the Upselected $\left(F_{1,372}=14.07, P<0.001\right)$ and Control lines $\left(F_{1,372}=16.14, P<0.001\right)$ and for $M_{\text {low }}$ in the Controls $\left(F_{1,372}=10.58, P<0.002\right)$. No significant differences were found for the Low-selected lines. The proportion of individuals falling under the lower mode $\left(P_{\text {low }}\right)$ was not significantly different between the two days for any selection treatment. Thus, although $T_{\mathrm{kd}}$ does drop with age, it is the means of the modes along the thermal gradient, not the bimodality itself, that are changing.

\section{Bimodality in other populations}

The lines used in the present study were collected in North America. We also measured $T_{\mathrm{kd}}$ on D. melanogaster from two other continents to see if this trait exhibits a bimodal distribution in other populations. European flies were represented by Linda Partridge's long-term selection lines (flies reared at $16.5 / 18^{\circ}, 25^{\circ}$ or $29^{\circ} \mathrm{C}$ under laboratory natural selection) which were originally collected in England over 10 years ago (Huey et al., 1991; Partridge et al., 1995). The Australian flies were from 13 populations collected along a latitudinal transect by Avis James and Linda Partridge (James et al., 1995). The parameter estimates for the distributions are summarised in Table 3. The distribution of $T_{\mathrm{kd}}$ is significantly better explained by a bimodal model in nine out of nine male and six out of nine female lines in the British flies, and in 12 out of 13 male and nine out of 13 female lines in the Australian flies.

In contrast, the $T_{\mathrm{kd}} \mathrm{S}$ of a distantly related drosophilid, Drosophila subobscura, sampled from six populations along the west coast of North America, all exhibit a unimodal distribution (mean $\pm \mathrm{SD}$; females: $M_{\mathrm{u}}=38.20 \pm 0.370, S_{\mathrm{u}}=1.12 \pm 0.267$; males: $M_{\mathrm{u}}=$ $38.51 \pm 0.383, S_{\mathrm{u}}=1.05 \pm 0.130$ ), similar in position and shape to the lower mode of $D$. melanogaster.

\section{Response trajectories}

The response trajectories for selection on knockdown temperature of females are shown in Fig. 3. The coefficients of the cubic polynomial regression lines depicted in Fig. 3 are listed in Table 4 (statistics included for both sexes). The Up-selected lines showed a linear increase in $M_{\mathrm{u}}$ until approximately generation 20, at which point the selection response began to plateau (Fig. 3a, Table 4). The response in $M_{\mathrm{u}}$ over the first 20 generations reflected both a reduction in the proportion of the population under the lower mode $\left(P_{\text {low }}\right.$, Fig. $\left.3 c\right)$ and a small increase in the value of the mean of $M_{\text {high }}$ (Fig. 3d). After generation 25, virtually no flies were left under the low mode. Thus Up-selection led to a loss of the lower mode and a slight shift (Table 1) in the mean of the upper mode. The variance

Table 2 Mean $( \pm \mathrm{SD}$ ) difference between various distribution parameters of 5-day-old VS. 6-day-old Drosophila melanogaster across all generations. The numbers in parentheses are the numbers of generations summarized in the statistics

\begin{tabular}{lcrrrr}
\hline Trt & Sex & \multicolumn{1}{c}{$M_{\mathrm{u}}$} & \multicolumn{1}{c}{$M_{\text {low }}$} & \multicolumn{1}{c}{$M_{\text {high }}$} & $P_{\text {low }}$ \\
\hline Con & F & $0.22 \pm 0.370(32)$ & $0.18 \pm 0.554(32)$ & $0.32 \pm 0.878(30)$ & $0.01 \pm 0.240(32)$ \\
& M & $0.17 \pm 0.330(32)$ & $0.09 \pm 0.312(32)$ & $0.05 \pm 0.518(31)$ & $-0.03 \pm 0.140(32)$ \\
High & F & $0.17 \pm 0.288(32)$ & $-0.04 \pm 0.592(32)$ & $0.15 \pm 0.311(32)$ & $-0.02 \pm 0.107(32)$ \\
& M & $0.12 \pm 0.308(32)$ & $-0.17 \pm 0.687(32)$ & $0.07 \pm 0.294(32)$ & $-0.03 \pm 0.075(32)$ \\
Low & F & $0.09 \pm 0.251(12)$ & $0.03 \pm 0.491(12)$ & $0.80 \pm 1.189(12)$ & $0.11 \pm 0.135(12)$ \\
& M & $-0.05 \pm 0.362(12)$ & $-0.07 \pm 0.261(12)$ & $-0.45 \pm 2.101(12)$ & $-0.08 \pm 0.278(12)$ \\
\hline
\end{tabular}

Table 3 Parameter estimates for unimodal and bimodal distributions of knockdown temperature for Drosophila melanogaster collected in the UK and Australia. The values shown are the mean and SD of the various lines

\begin{tabular}{lccccrr}
\hline Locale & Sex & $N$ & $M_{\mathrm{u}}$ & $M_{\text {low }}$ & $M_{\text {high }}$ & $P_{\text {low }}$ \\
\hline UK & F & 9 & $38.35 \pm 0.452$ & $38.11 \pm 0.466$ & $40.21 \pm 1.060$ & $0.85 \pm 0.120$ \\
& $\mathrm{M}$ & 9 & $38.34 \pm 0.474$ & $38.00 \pm 0.454$ & $40.73 \pm 0.410$ & $0.88 \pm 0.061$ \\
Australia & $\mathrm{F}$ & 13 & $39.31 \pm 0.343$ & $38.79 \pm 0.576$ & $40.53 \pm 0.767$ & $0.70 \pm 0.217$ \\
& $\mathrm{M}$ & 13 & $39.16 \pm 0.363$ & $38.41 \pm 0.507$ & $40.55 \pm 0.311$ & $0.66 \pm 0.131$ \\
\hline
\end{tabular}


of $\mathrm{T}_{\mathrm{kd}}$ within the Up-selected lines dropped steadily during selection (Fig. 3b, Table 4).

The evolution of $M_{\mathrm{u}}$ in the Low-selected lines (Fig. 3a, Table 4) involved both a rapid shifting of flies from the upper to the lower mode of the distribution (Fig. 3c) and a downward shift in $M_{\text {low }}$ (Fig. 3d). Because the Low lines were selected for a targeted range of temperatures rather than an extreme, the directional component of selection diminished as $M_{\mathrm{u}}$ converged on the targeted temperature (approximately generation 26). The variance for $M_{\mathrm{u}}$ dropped rapidly in the first few generations of selection (Fig. 3b), but showed no significant linear decrease over the course of the experiment (Table 4). In spite of the stabilizing selection on $M_{\text {low }}$, no significant linear change was observed for $S_{\text {low }}$ over the course of the experiment (Table 4).

Females in the Control lines showed a slight decrease in $M_{\mathrm{u}}, M_{\text {low }}$ and $M_{\text {high }}$ throughout the course of the experiment (Fig. 3a, Table 4), whereas males showed no significant trends. No linear change in the proportion of individuals under the two modes was detected for either sex.
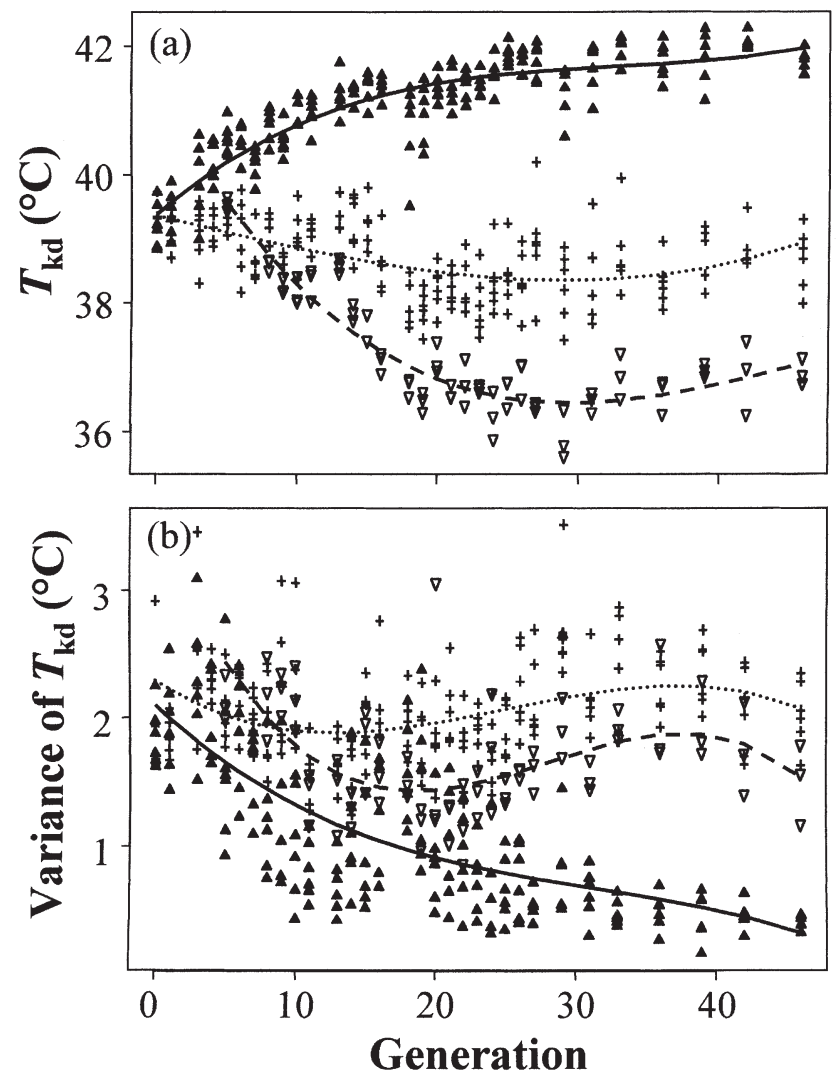

Although the increase in $M_{\mathrm{u}}$ for the Up-selected lines was dramatic, the maximum $T_{\mathrm{kd}}$ within those lines did not evolve in response to selection. We tested this by comparing the highest temperature at which any individual fell out of the Weber column in the 'early' generations $(0,1$ and 3$)$ vs. the 'late' generations $(39,42$ and 46) for each of the six Up-selected lines. No significant difference in the maximum $T_{\mathrm{kd}}$ was observed for females (early $\bar{x} \pm \mathrm{SD}$ : $43.14 \pm 0.427^{\circ} \mathrm{C}$; late: $43.28 \pm 0.354^{\circ} \mathrm{C}$; paired $t$-test: $t_{5}=-1.39, P=0.22$ ) or for males (early: $42.83 \pm 0.486^{\circ} \mathrm{C}$; late: $43.19 \pm$ $0.359^{\circ} \mathrm{C}$; paired $t$-test: $t_{5}=-1.57, P=0.18$ ).

\section{Heritability estimates}

The response to selection, as a function of cumulative selection differential, is shown in Fig. 4 (males are shown; the plots for females are similar). Figure 4(a) is the plot for $M_{\mathrm{u}}$; Fig. 4(b) shows the response of $M_{\mathrm{high}}$ in the Up-selected lines and $M_{\text {low }}$ in the Low-selected lines. The slopes of the regression over the first 10 generations of selection (solid bold lines, Fig. 4) provide the estimate
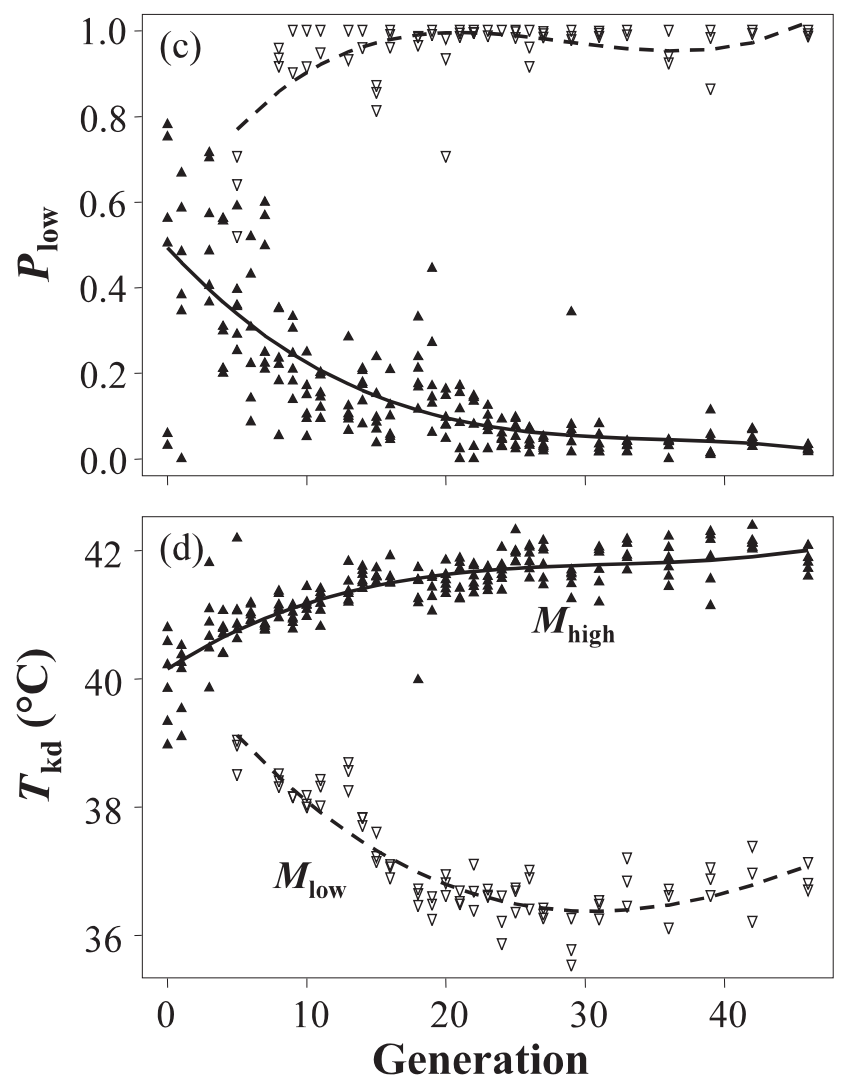

Fig. 3a-d Response trajectories for (a) mean $T_{\mathrm{kd}}$, (b) the variance of $T_{\mathrm{kd}}$ (c) the proportion of the knocked-down flies under the lower mode $\left(P_{\text {low }}\right)$ and (d) $M_{\text {low }}$ for the Low-selected and $M_{\text {high }}$ for the Up-selected flies over the 46 generations of rearing. The lines are third-order polynomial regressions (estimated parameters in Table 4). Female response trajectories are shown; the trajectories for males are similar.

(C) The Genetical Society of Great Britain, Heredity, 83, 15-29. 
Table 4 Coefficients of the cubic polynomial regression lines of the mean $\left(M_{\mathrm{x}}\right)$ and the variance $\left(S_{\mathrm{x}}{ }^{2}\right)$ of knockdown temperature on generation for the trajectories of the Up, Low and Control selection treatment in Drosophila melanogaster. The proportion of individuals under the lower mode $\left(P_{\text {low }}\right)$ was arcsine square root transformed prior to analysis. Trt, selection treatment; Stat, statistic; Con, control

\begin{tabular}{|c|c|c|c|c|c|c|c|c|c|}
\hline \multirow[b]{2}{*}{ Trt } & \multirow[b]{2}{*}{ Stat } & \multicolumn{4}{|c|}{ Female } & \multicolumn{4}{|c|}{ Male } \\
\hline & & Linear & Quadratic & Cubic & $R^{2}$ & Linear & Quadratic & Cubic & $R^{2}$ \\
\hline \multirow{7}{*}{ Con } & $M_{\mathrm{u}}$ & $-2.67 * * *$ & $3.01 * * *$ & 0.51 & 0.282 & -0.38 & $2.29 * * *$ & 0.30 & 0.138 \\
\hline & $S_{\mathrm{u}}^{2}$ & 0.45 & 0.74 & -0.44 & 0.073 & $0.71 * *$ & $0.83^{* *}$ & $-0.96^{* * *}$ & 0.154 \\
\hline & $M_{\text {low }}$ & $-2.92 * * *$ & $2.64 * *$ & 0.48 & 0.126 & -0.52 & $1.66^{* *}$ & 0.37 & 0.061 \\
\hline & $S_{\text {low }}^{2}$ & 0.65 & $2.42 * *$ & -0.33 & 0.054 & $1.06 * *$ & $2.29 * * *$ & $-1.58 * * *$ & 0.291 \\
\hline & $M_{\text {high }}$ & $-3.11 * * *$ & $3.19 * * *$ & 1.22 & 0.147 & -0.18 & 1.04 & 0.10 & 0.014 \\
\hline & $S_{\text {high }}^{2}$ & 1.75 & $-3.74 * * *$ & -0.14 & 0.110 & 0.46 & $-2.44 * *$ & 0.28 & 0.048 \\
\hline & $P_{\text {low }}$ & -0.35 & -0.11 & 0.18 & 0.009 & -0.05 & -0.39 & -0.08 & 0.019 \\
\hline \multirow[t]{7}{*}{$\mathrm{Up}$} & $M_{\mathrm{u}}$ & $8.28 * * *$ & $-3.63^{* * *}$ & $1.22 * * *$ & 0.799 & $9.34 * * *$ & $-4.20 * * *$ & $1.33^{* * *}$ & 0.839 \\
\hline & $S_{\mathrm{u}}^{2}$ & $-5.55^{* * *}$ & $1.43 * * *$ & -0.43 & 0.526 & $-6.34 * * *$ & $2.33 * * *$ & -0.13 & 0.626 \\
\hline & $S_{\text {low }}^{2}$ & 2.42 & $-3.30^{*}$ & $-2.91^{*}$ & 0.074 & 0.77 & -0.86 & -0.81 & 0.010 \\
\hline & $M_{\text {low }}$ & $2.55^{* * *}$ & -0.83 & $2.04 * *$ & 0.135 & $3.85^{* * * *}$ & $-1.60 * *$ & 0.90 & 0.228 \\
\hline & $M_{\text {high }}$ & $5.99 * * *$ & $-2.79 * * *$ & $1.07 * * *$ & 0.725 & $5.87 * * *$ & $-2.19 * * *$ & 0.43 & 0.755 \\
\hline & $S_{\text {high }}^{2}$ & $-0.83 * * *$ & $0.66 * * *$ & $-0.78 * * *$ & 0.272 & $-0.34 * * *$ & 0.12 & -0.15 & 0.096 \\
\hline & $P_{\text {low }}$ & $-2.09 * * *$ & $0.77 * * *$ & -0.02 & 0.564 & $-2.42 * * *$ & $1.22 * * *$ & $-0.33 * *$ & 0.664 \\
\hline \multirow[t]{7}{*}{ Low } & $M_{\mathrm{u}}$ & $-5.21 * * *$ & $4.89 * * *$ & $-0.91^{*}$ & 0.846 & $-4.00 * * *$ & $4.37 * * *$ & -0.65 & 0.820 \\
\hline & $S_{\mathrm{u}}^{2}$ & -0.38 & $1.39 * * *$ & $-1.53 * * *$ & 0.418 & 0.35 & $1.84 * * *$ & $-1.66^{* * *}$ & 0.482 \\
\hline & $M_{\text {low }}$ & $-4.7 * * *$ & $4.34 * * *$ & -0.39 & 0.756 & $-3.68 * * *$ & $3.54 * * *$ & -0.47 & 0.804 \\
\hline & $S_{\text {low }}^{2}$ & 0.01 & $1.13 * *$ & $-1.43 * * *$ & 0.314 & 0.35 & $1.19^{* * *}$ & $-2.13 * * *$ & 0.447 \\
\hline & $M_{\text {high }}$ & -1.62 & 1.68 & -0.32 & 0.025 & -0.29 & 1.06 & -1.32 & 0.060 \\
\hline & $S_{\text {high }}^{2}$ & -0.72 & -0.35 & 1.36 & 0.076 & -1.39 & -1.22 & $2.49^{*}$ & 0.078 \\
\hline & $P_{\text {low }}$ & $0.49 * * *$ & $-0.48 * * *$ & $0.45^{* *}$ & 0.486 & $0.41^{*}$ & $-0.71 * * *$ & 0.05 & 0.253 \\
\hline
\end{tabular}

$t$-tests for difference from zero: ${ }^{* * *} P<0.001 ; * * P<0.01 ; * P<0.05$.

of realized heritability; heritabilities of the unimodal mean and of the two means from the bimodal distribution are reported in Table 5.

All of the heritability estimates for $M_{\mathrm{u}}$ were significantly different from zero. Males and females scored similarly. The heritability of $M_{\mathrm{u}}$ in the Up-selected lines was around 0.12 , whereas that for the Low lines was $\approx 0.19$. Within each selection treatment, the heritabilities of the positively selected modes (i.e. $M_{\text {low }}$ in the Lowselected lines and $M_{\text {high }}$ in the Up-selected lines) were higher than the heritabilities of the modes being selected against (Table 3). The heritability estimates were significantly heterogeneous among the replicates within a selection treatment for three of the 12 values estimated (Table 5).

The change in heritability over the course of the experiment is depicted in Fig. 5. The mean heritability $\pm 1 \mathrm{SD}$, computed over a sliding window of 10 selection episodes, is plotted as a function of generation. Figure 5(a) depicts the change in heritability of $M_{\mathrm{u}}$; Fig. 5(b) depicts the change in $M_{\text {low }}$ for the Lowselected and $M_{\text {high }}$ for the up-selected lines. The Upselected lines show little decline in heritability until after generation 15; thereafter the heritability of both $M_{\mathrm{u}}$ and $M_{\text {high }}$ declines fairly steadily.

In contrast, the heritabilities of both $M_{\mathrm{u}}$ and $M_{\text {low }}$ in the Low-selected lines show a strong and rapid increase until generation 26-27 (Fig. 5a,b). Recall that the Lowselection regime focuses on a target temperature of $37^{\circ} \mathrm{C}$; at generation 26 , both $M_{\mathrm{u}}$ and $M_{\text {low }}$ had reached $37^{\circ} \mathrm{C}$, so most directional selection ceased. The plummet in the heritability estimates at that point occurred because the directional response to selection approached zero, as shown by the wandering trajectory in Fig. 4 .

\section{Response to relaxation of selection}

In generation 23, samples from three Up-selected lines were removed from selection to see if their $T_{\mathrm{kd}}$ would regress towards the controls. These populations were maintained in the same manner as the selection lines during generations when we did not select on knockdown temperature (see Materials and methods). We compared $M_{\mathrm{u}}, M_{\text {low }}, M_{\text {high }}$ and $P_{\text {low }}$ of these Relaxed selection lines in generation 46 with those of their paired source populations (Up-selected in generation 23) and 
Fig. 4 The response to selection as a function of the cumulative selection differential. The solid regression lines represent the mean heritability over the first 10 selection episodes. (a) $M_{\mathrm{u}}$ for the Up-selected lines and the Low-selected lines. (b) $M_{\text {high }}$ for the Up-selected lines and $M_{\text {low }}$ for the Low-selected lines.

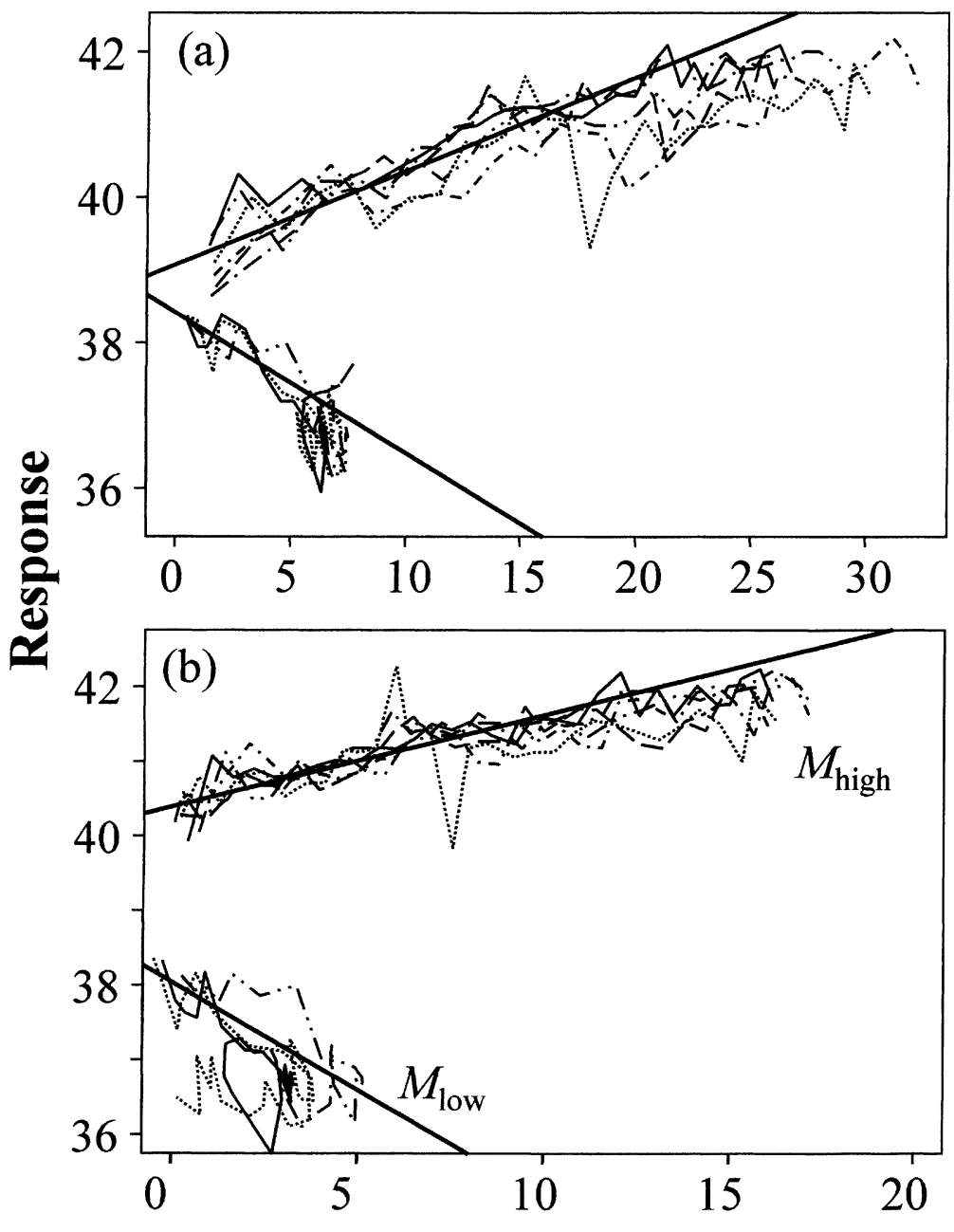

Cumulative selection differential

Table 5 Realized heritability estimates of the unimodal and bimodal means of knockdown temperature in Drosophila melanogaster over the first 10 generations. The $t$-statistic tests the null hypothesis that the regression coefficient of the mean trait value on the cumulative selection differential is not significantly different from zero. The asterisk by the heritability estimate indicates that there was significant heterogeneity $(P<0.05)$ among the lines within the selection treatment (by ANOVA). Trt, selection treatment; Stat, statistic

\begin{tabular}{|c|c|c|c|c|c|c|c|}
\hline \multirow[b]{2}{*}{ Trt } & \multirow[b]{2}{*}{ Stat } & \multicolumn{3}{|c|}{ Female } & \multicolumn{3}{|c|}{ Male } \\
\hline & & $h^{2}(\mathrm{SE})$ & $t$ & $P$ & $h^{2}(\mathrm{SE})$ & $t$ & $P$ \\
\hline \multirow[t]{3}{*}{ Up } & $M_{\mathrm{u}}$ & $0.12(0.012)^{*}$ & 9.84 & 0.0000 & $0.13(0.01)^{*}$ & 12.94 & 0.0000 \\
\hline & $M_{\text {low }}$ & $0.02(0.009) *$ & 1.97 & 0.0553 & $0.03(0.007)$ & 4.23 & 0.0001 \\
\hline & $M_{\text {high }}$ & $0.15(0.025)$ & 5.89 & 0.0000 & $0.12(0.017)$ & 7.21 & 0.0000 \\
\hline \multirow[t]{3}{*}{ Low } & $M_{\mathrm{u}}$ & $0.19(0.032)$ & 6.11 & 0.0000 & $0.19(0.032)$ & 5.95 & 0.0000 \\
\hline & $M_{\text {low }}$ & $0.30(0.041)$ & 7.34 & 0.0000 & $0.29(0.056)$ & 5.17 & 0.0001 \\
\hline & $M_{\text {high }}$ & $0.10(0.055)$ & 1.84 & 0.1076 & $0.09(0.045)$ & 1.94 & 0.0815 \\
\hline
\end{tabular}




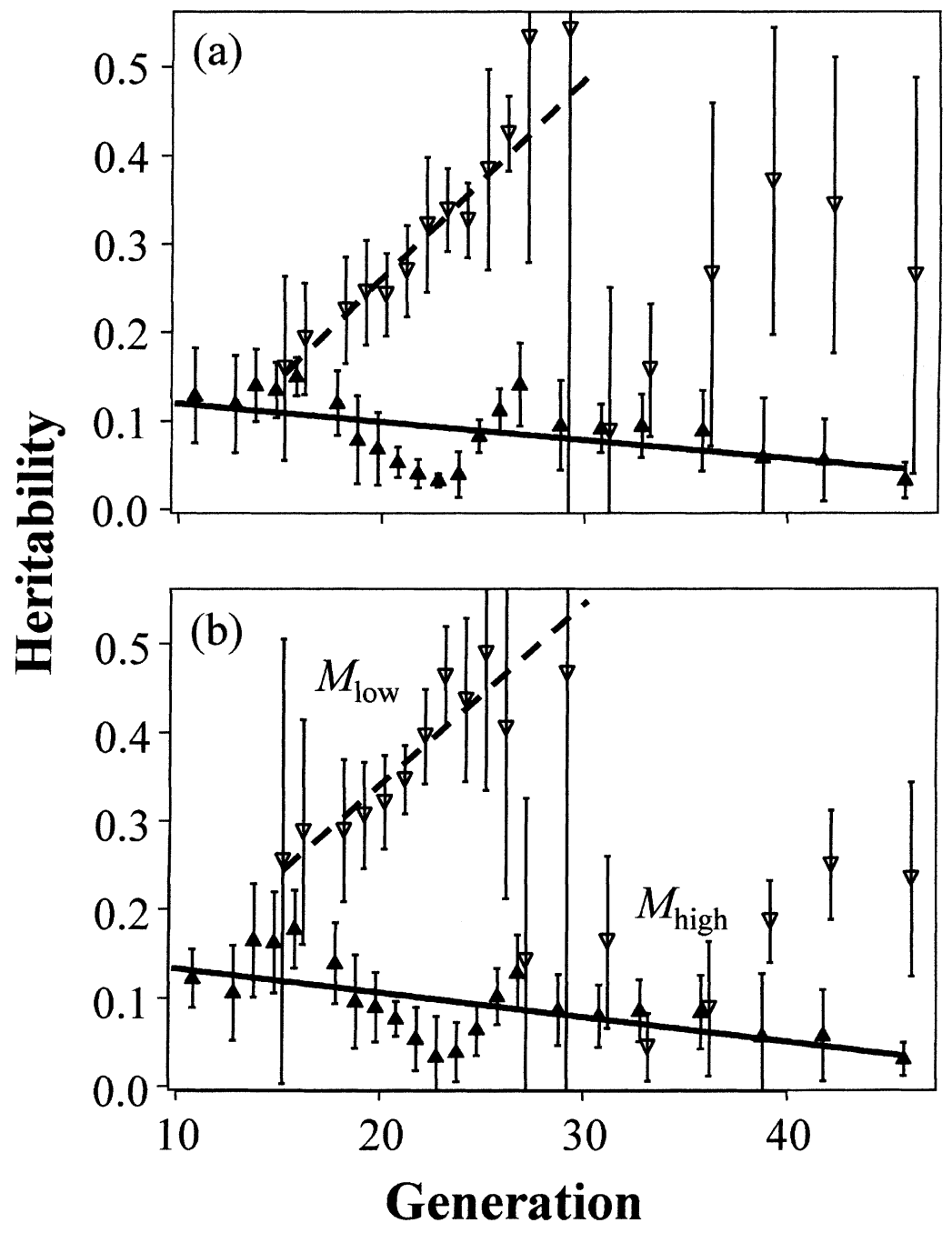

Fig. 5 The change in heritability over the course of the experiment. Plotted is the mean \pm 1 SD for a sliding window of 10 selection episodes ending at a given generation. (a) The change in $M_{\mathrm{u}}$. The regression lines are for heritabilities over all generations for the Up-selected lines $\left(h^{2}=0.1409-0.0021\right.$ Generation, $R^{2}=0.1582, F_{1,130}=24.43$, $\mathrm{P}<0.001)$ and for generations 16 to 26 for the Low-selected lines $\left(h^{2}=-0.1844+0.0225\right.$ Generation, $R^{2}=0.6923, F_{1,28}=62.99$, $P<0.001)$. (b) The change in $M_{\text {high }}$ for Up-selected lines (over all generations: $h^{2}=0.1614-0.0027$ Generation, $R^{2}=0.2208, F_{1,130}=36.84$, $P<0.001)$ and the change in $M_{\text {low }}$ for the Low-selected lines (over generations 16 through $26 ; M_{\text {low }}$ : $h^{2}=-0.0607+0.0203$ Generation, $R^{2}=0.3955, F_{1,28}=18.32$, $P<0.001)$. also with those of the selected populations in generation 46 (after 12 intervening selection episodes) using paired $t$-tests with sequential Bonferroni tablewise significance corrections (Rice, 1989). None of the unimodal or bimodal traits in the generation 23 source populations differed significantly from those in the generation 46 Relaxed selection populations (Table 4). $M_{\mathrm{u}}$ and $M_{\text {high }}$ were greater for females in the generation 46 selection lines than for females in the generation 46 Relaxed selection lines, reflecting the small increase in these values resulting from continued selection. From generation 23 to generation 46, $M_{\mathrm{u}}$ in the control lines increased very slightly; none of the changes in the bimodal parameters, however, was significant (Table 6).

\section{Discussion}

Knockdown temperature is bimodally distributed in nearly every population of $D$. melanogaster we have surveyed from England, Australia and North America (Fig. 1, Tables 1 and 3). The distribution of $T_{\mathrm{kd}}$ of flies from North America responded dramatically to selection. The lower mode largely disappeared from the Up-selected lines within 20 generations of selection (mean \pm SD selection intensity: $0.92 \pm 0.119$, pooled across replicates and sexes). Similarly, the upper mode largely disappeared from the Low-selected lines within 20 generations of selection (selection intensity: $0.49 \pm 0.348$ ). Furthermore, although selection dramatically increased mean knockdown temperatures in the Up-selected lines, we observed no significant increase in the maximum knockdown temperature over the course of the experiment. Thus knockdown temperature of $D$. melanogaster seemingly has an upper limit of $\approx 44^{\circ} \mathrm{C}$.

Three previous studies have selected on increased knockdown time (McColl et al., 1966; Hoffmann et al., 1997; Bubli et al., 1998), the time flies exposed to a stressful temperature can maintain a grip on the 
Table 6 Mean knockdown temperature in Drosophila melanogaster for samples of Up lines removed form selection ("Relaxed selection lines") in generation 23 and samples retained in the Up-selected regime. Differences between generations and lines are tested using paired $t$-tests, which are shown beneath the pair of statistics being tested. Trt, selection treatment; Con, control; Gen, generation

\begin{tabular}{|c|c|c|c|c|c|}
\hline Trait & Sex & $\operatorname{Trt}$ & Gen & Mean $\pm \mathrm{SD}$ & $t$-test \\
\hline \multirow[t]{2}{*}{$M_{\mathrm{u}}$} & $\mathrm{F}$ & $\begin{array}{l}\text { Up } \\
\text { Rest } \\
\text { Up } \\
\text { Con } \\
\text { Con }\end{array}$ & $\begin{array}{l}23 \\
46 \\
46 \\
23 \\
46\end{array}$ & $\begin{array}{l}41.71 \pm 0.228 \\
41.60 \pm 0.164 \\
42.09 \pm 0.195 \\
38.21 \pm 0.518 \\
38.93 \pm 0.526\end{array}$ & $\begin{array}{l}\} t=1.84 ; P=0.208 \\
\} t=27.84 ; P=0.001^{*} \\
\} t=-3.86 ; P=0.012^{*}\end{array}$ \\
\hline & M & $\begin{array}{l}\text { Up } \\
\text { Rest } \\
\text { Up } \\
\text { Con } \\
\text { Con }\end{array}$ & $\begin{array}{l}23 \\
46 \\
46 \\
23 \\
46\end{array}$ & $\begin{array}{l}41.59 \pm 0.134 \\
41.44 \pm 0.284 \\
41.94 \pm 0.378 \\
38.24 \pm 0.389 \\
39.12 \pm 0.493\end{array}$ & $\begin{array}{l}\} t=1.91 ; P=0.196 \\
\} t=4.15 ; P=0.054 \\
\} t=-3.97 ; P=0.011^{*}\end{array}$ \\
\hline \multirow[t]{2}{*}{$M_{\text {low }}$} & $\mathrm{F}$ & $\begin{array}{l}\text { Up } \\
\text { Rest } \\
\text { Up } \\
\text { Con } \\
\text { Con }\end{array}$ & $\begin{array}{l}23 \\
46 \\
46 \\
23 \\
46\end{array}$ & $\begin{array}{l}39.62 \pm 0.519 \\
39.62 \pm 1.025 \\
39.90 \pm 0.122 \\
37.87 \pm 0.139 \\
38.49 \pm 0.569\end{array}$ & $\begin{array}{l}\} t=0.03 ; P=0.982 \\
\} t=0.66 ; P=0.579 \\
\} t=-2.21 ; P=0.078\end{array}$ \\
\hline & M & $\begin{array}{l}\text { Up } \\
\text { Rest } \\
\text { Up } \\
\text { Con } \\
\text { Con }\end{array}$ & $\begin{array}{l}23 \\
46 \\
46 \\
23 \\
46\end{array}$ & $\begin{array}{l}39.50 \pm 0.319 \\
39.97 \pm 1.265 \\
39.30 \pm 0.692 \\
38.04 \pm 0.471 \\
38.47 \pm 0.352\end{array}$ & $\begin{array}{l}\} t=-0.72 ; P=0.548 \\
\} t=-1.71 ; P=0.337 \\
\} t=-2.88 ; P=0.035\end{array}$ \\
\hline \multirow[t]{2}{*}{$M_{\text {high }}$} & $\mathrm{F}$ & $\begin{array}{l}\text { Up } \\
\text { Rest } \\
\text { Up } \\
\text { Con } \\
\text { Con }\end{array}$ & $\begin{array}{l}23 \\
46 \\
46 \\
23 \\
46\end{array}$ & $\begin{array}{l}41.87 \pm 0.139 \\
41.67 \pm 0.202 \\
42.15 \pm 0.221 \\
38.68 \pm 0.786 \\
40.30 \pm 0.747\end{array}$ & $\begin{array}{l}\} t=5.46 ; P=0.032 \\
\} t=42.78 ; P=0.001^{*} \\
\} t=-1.75 ; P=0.155\end{array}$ \\
\hline & M & $\begin{array}{l}\text { Up } \\
\text { Rest } \\
\text { Up } \\
\text { Con } \\
\text { Con }\end{array}$ & $\begin{array}{l}23 \\
46 \\
46 \\
23 \\
46\end{array}$ & $\begin{array}{l}41.70 \pm 0.065 \\
41.67 \pm 0.202 \\
42.15 \pm 0.221 \\
39.48 \pm 1.433 \\
40.41 \pm 0.225\end{array}$ & $\begin{array}{l}\} t=2.10 ; P=0.171 \\
\} t=42.78 ; P=0.001^{*} \\
\} t=-3.04 ; P=0.056\end{array}$ \\
\hline \multirow[t]{2}{*}{$P_{\text {low }}$} & $\mathrm{F}$ & $\begin{array}{l}\text { Up } \\
\text { Rest } \\
\text { Up } \\
\text { Con } \\
\text { Con }\end{array}$ & $\begin{array}{l}23 \\
46 \\
46 \\
23 \\
46\end{array}$ & $\begin{array}{l}0.08 \pm 0.062 \\
0.03 \pm 0.003 \\
0.03 \pm 0.008 \\
0.56 \pm 0.383 \\
0.74 \pm 0.217\end{array}$ & $\begin{array}{l}\} t=1.50 ; P=0.272 \\
\} t=-2.17 ; P=0.162 \\
\} t=0.75 ; P=0.489\end{array}$ \\
\hline & M & $\begin{array}{l}\text { Up } \\
\text { Rest } \\
\text { Up } \\
\text { Con } \\
\text { Con }\end{array}$ & $\begin{array}{l}23 \\
46 \\
46 \\
23 \\
46\end{array}$ & $\begin{array}{l}0.06 \pm 0.039 \\
0.05 \pm 0.002 \\
0.03 \pm 0.038 \\
0.75 \pm 0.272 \\
0.66 \pm 0.124\end{array}$ & $\begin{array}{l}\} t=0.52 ; P=0.658 \\
\} t=-1.14 ; P=0.371 \\
\} t=-1.50 ; P=0.194\end{array}$ \\
\hline
\end{tabular}

* Significant at $P<0.05$ level by the sequential Bonferroni correction for tables of statistics (Rice, 1989).

knockdown column. The two measures are certainly related, because flies selected for a high knockdown temperature also have an increased knockdown time and vice versa (Huey \& Gilchrist, unpubl. data), but details of the responses differ. First, knockdown time has a unimodal distribution rather than the bimodal distribution of knockdown temperature. Even populations of $D$. melanogaster that have been subjected to several generations of selection for long knockdown time retain a bimodal distribution for $T_{\mathrm{kd}}$. Secondly, 
knockdown time measures resistance to a chronic, constant high temperature stress, whereas $T_{\mathrm{kd}}$ measures resistance to an increasing temperature stress. Although time under heat stress is unavoidably correlated with the temperature increase, our results indicate that our selection lines have diverged in sensitivity to temperature, not just in knockdown time. Finally, the previous studies have selected for increased knockdown resistance only; ours is the first also to examine both up and down selection on a knockdown trait.

The realized heritability provides an estimate of the additive genetic variation present in the population. The values for $M_{\mathrm{u}}$ in the $\mathrm{Up}$-selected lines, measured over the first 10 generations (Table 5), are similar to those measured for increased knockdown time by McColl et al. (1996; estimate of 0.08-0.11) and Bubli et al. (1998; estimate of 0.05-0.10), but higher than the mean realized heritability $(\approx 0.07)$ of a wide range of physiological traits (Mousseau \& Roff, 1987). Huey et al. (1992) reported a realized heritability for increased knockdown temperature of 0.28 ; but that estimate was made over only four generations of selection.

Selection seems to have exhausted much of the genetic variation in the Up-selected lines, particularly for $M_{\text {high }}$. The variance both among (Fig. 3a) and within (Fig. 3b) the Up-selected lines greatly decreased over the course of selection. The heritability of $M_{\text {high }}$ declined from 0.1 to 0.15 in the first 10 generations to near zero in the last 10 generations (Fig. 5b), suggesting that the genes responsible for high $T_{\mathrm{kd}}$ were near fixation.

Selection had a remarkable effect on the realized heritability of $T_{\mathrm{kd}}$. Between generations 5 and 26, the heritability of both $M_{\mathrm{u}}$ and $M_{\text {low }}$ in each of the Lowselected lines approximately doubled (Fig. 5). Although the selection differential decreased in each generation as the population moved towards the target $T_{\mathrm{kd}}$ of $37^{\circ} \mathrm{C}$, the response to selection remained nearly constant. This rapid rise in heritability suggests the involvement of one or more major genes influencing $T_{\mathrm{kd}}$ (Latter, 1965; Frankham \& Nurthen, 1981). If an allele were initially at low frequency in the source population, the additive genetic variance would initially increase, and then decline, as selection carried that allele towards fixation. The rapid decline in heritability after generation 26 (Fig. 5) is at least partly caused by the selection differential dropping to near zero as the population reached the target $T_{\mathrm{kd}}$, but may also reflect the decline in additive genetic variance as the allele of major effect approached fixation. Stabilizing selection on the Lowselected flies did not reduce the variation in $M_{\text {low }}$ over the course of the experiment (Fig. 3, Table 4).

The behaviour of the flies during heating may provide clues as to the functional basis of knockdown temperatures. Knockdown occurs when a fly loses its ability to grip the baffles or walls of a Weber column. The Upselected flies retain control of their limbs as the temperature rises; they remain clustered near the top of the column until a sudden and catastrophic loss of locomotory function sends the fly tumbling to the bottom of the column. In contrast, flies from the Lowselected lines gradually work their way towards the bottom of the tube as the temperature rises; they lose control of their limbs momentarily but recover; however, each fall carries them lower and lower in the column. Hoffmann et al. (1997) noted a similar behavioural response to selection on knockdown time. In any case, the flies are temporarily immobilized when they come out of the column, usually lying on their backs with legs twitching. This pattern of behaviour is similar to that produced by some temperature sensitive mutations of channel proteins affecting neurological activity (e.g. Grigliatti et al. 1972; Jackson et al. 1985). Complementation tests showed that the two modes were not caused by allele variation at comatose, the only $\mathrm{X}$-linked channel mutant known to have this phenotype (A. G. Clark, pers. comm.).

Several lines of evidence suggest that one or two loci of large effect, plus some additive modifiers, largely control knockdown temperature. First, the clear and consistent bimodality of the trait (Figs 1 and 2) indicates something other than simple quantitative inheritance. Secondly, much of the selection in both the Up- and Low-selected lines over the first 25 generations consisted in moving individuals from one mode to the other, rather than shifting the position of the modes. Thirdly, Up-selected lines removed from selection at generation 23 showed virtually no regression towards the control means (Table 4), suggesting that the genes controlling this trait were either near fixation or conveyed no fitness disadvantage. Fourthly, the rise in heritability of $M_{\mathrm{u}}$ and $M_{\text {low }}$ in the Low-selected lines from generations 1026 (Fig. 5) suggests an allele of large effect (Latter, 1965; Frankham \& Nurthen, 1981). Finally, exploratory crosses between Up- and Low-selected (Gilchrist \& Huey, unpubl. data) lines suggest the presence of at least one major Mendelian factor. Of course, more complete genetic analyses now need to be carried out to clarify the genetic architecture underlying knockdown temperature. Validation of the hypothesized major-gene effect would raise an interesting question: what selective factors maintain a genetic polymorphism that appears to be worldwide and that persists even in a long-term laboratory stock?

\section{Acknowledgements}

These experiments could not have been carried out without the assistance of Mary Lamb, Kimura Ward 
and Marilyn Howe. Critical comments on the manuscript were provided by Joel Kingsolver, Ary Hoffmann, Andrew Clark and one anonymous reviewer. Bob Byers and other members of the S-News listserver supplied invaluable statistical advice. The brown eye-colour mutants were provided by Stephen Henikoff, Fred Hutchinson Cancer Research Center This project was supported by National Science Foundation grant BSR9301151 to R.B.H.

\section{References}

BENNETT, A. F., LENSKI, R. E. AND MITTLER, J. E. 1992. Evolutionary adaptation to temperature. I. Fitness responses of Escherichia coli to changes in its thermal environment. Evolution, 46, 16-30.

BUBli, O. A., IMASHEVA, A. G. AND LOESCHCKE, v. 1998. Selection for knockdown resistance to heat in Drosophila melanogaster at high and low larval densities. Evolution, 52, 619-625.

CASEY, T. M. AND HEGEL, J. R. 1981. Caterpillar setae: insulation for an ectotherm. Science, 214, 1131-1133.

CAVICCHI, S., GUERRA, D., GIORGI, G. AND PEZZOLI, C. 1985. Temperature-related divergence in experimental populations of Drosophila melanogaster. I. Genetic and developmental basis of wing size and shape variation. Genetics, 109, 665-689.

ClARKE, A. 1996. The influence of climate change on the distribution and evolution of organisms. In: Johnson, I. A. and Bennett, A. F. (eds) Animals and Temperature: Phenotypic and Evolutionary Adaptation, pp. 377-407. Cambridge University Press, Cambridge.

ClAyton, G. A., MORRIS, J. A. AND Robertson, A. 1957. An experimental check on quantitative genetical theory. I. Short-term responses to selection. J. Genet., 55, 131-151. COYNE, J. A., BUNDGAARD, J. AND PROUT, T. 1983. Geographic variation of tolerance to environmental stress in Drosophila pseudoobscura. Am. Nat., 122, 474-488.

DAVID, J. R. 1988. Temperature. In: Lints, F. A. and Soliman, M. H. (eds) Drosophila as a Model Organism for Aging, pp. 33-45. Blackie, Glasgow.

FALCONER, D. S. 1989. Introduction to Quantitative Genetics, 3rd edn. Longman, Harlow, UK.

FRANKHAM, R. AND NURTHEN, R. K. 1981. Forging links between population and quantitative genetics. Theor. Appl. Genet., 59, 251-263.

GRIGLIATTI, T. A., SUZUKI, D. T. AND WILLIAMSON, R. 1972. Temperature-sensitive mutations in Drosophila melanogaster. Part X. Developmental analysis of paralytic mutation. Devl. Biol., 28, 352-371.

GROMKo, M. H., GILBERT, D. G. AND RICHMOND, R. C. 1984. Sperm transfer and use in the multiple mating system of Drosophila. In: Smith, R. L. (ed.) Sperm Competition and the Evolution of Animal Mating Systems, pp. 371-426. Academic Press, Orlando, FL.

HOFFMANN, A. A. AND PARSONS, P. A. 1991. Evolutionary Genetics and Environmental Stress. Oxford University Press, Oxford. HOFFMANN, A. A., DAGHER, H., HERCUS, M. AND BERRIGAN, D. 1997. Comparing different measures of heat resistance in selected lines of Drosophila melanogaster. J. Insect Physiol., 43, 393-405.

HUEY, R. B. AND PIANKA, E. R. 1977. Patterns of niche overlap among broadly sympatric versus narrowly sympatric Kalahari lizards (Scincidae: Mabuya). Ecology, 58, 119-128.

HUEY, R. B., PARTRIDGE, L. AND FOWLER, K. 1991. Thermal sensitivity of Drosophila melanogaster responds rapidly to laboratory natural selection. Evolution, 45, 751-756.

HUEY, R. B., CRILL, W. D., KINGSOlVER, J. G. AND WEBER, K. E. 1992. A method for rapid measurement of heat or cold resistance of small insects. Funct. Ecol., 6, 489-494.

JACKSON, F. R., GITSCHIER, J., STRICHARTZ, G. R. AND HALL, L. M. 1985. Genetic modifications of voltage-sensitive sodium channels in Drosophila: gene dosage studies of the seizure locus. J. Neurosci., 5, 1144-1151.

JAMES, A. C., AZEVEDO, R. B. R. AND PARTRIDGE, L. 1995. Cellular basis and developmental timing in a size cline of Drosophila melanogaster. Genetics, 140, 659-666.

KINDRED, B. 1965. Selection for temperature sensitivity in scute Drosophila. Genetics, 52, 723-728.

LATTER, B. D. H. 1965. The response to artificial selection due to autosomal genes of large effect. I. Changes in gene frequency at an additive locus. Aust. J. Biol. Sci., 18, 585-598.

LEVINS, R. 1969. Thermal acclimation and heat resistance in Drosophila species. Am. Nat., 103, 483-499.

LYNCH, M. AND WALSH, B. 1998. Genetics and Analysis of Quantitative Traits. Sinauer Associates, Sunderland, MA.

MCCOLL, G., HOFFMANN, A. A. AND MCKECHNIE, S. W. 1996. Response of two heat shock genes to selection for knockdown heat resistance in Drosophila melanogaster. Genetics, 143, 1615-1627.

MORRISON, w. W. AND MILKMAN, R. 1978. Modification of heat resistance in Drosophila by selection. Nature, 273, 49-50.

MOUSSEAU, T. A. AND ROFF, D. A. 1987. Natural selection and the heritability of fitness components. Heredity, 59, 181-197.

PARTRIDGE, L., BARRIE, B., BARTON, N. H., FOWLER, K. AND FRENCH, V. 1995. Rapid laboratory evolution of adult lifehistory traits in Drosophila melanogaster in response to temperature. Evolution, 49, 538-544.

PENNYCUIK, P. R. 1979. Selection of laboratory mice for improved reproductive performance at high environmental temperatures. Aust. J. Biol. Sci., 32, 133-151.

QUINTANA, A. AND PREVOSTI, A. 1990. Genetic and environmental factors in the resistance of Drosophila subobscura adults to high temperature shock. II. Modification of heat resistance by indirect selection. Theor. Appl. Genet., 80, 847-851.

RICE, W. R. 1989. Analyzing tables of statistical data. Evolution, 43, 223-225.

StAtsci. 1993. S-Plus Users Manual. Statistical Sciences Inc., Seattle, WA.

STEPHANOU, G. AND ALAhiotis, S. N. 1983. Non-Mendelian inheritance of 'heat-sensitivity' in Drosophila melanogaster. Genetics, 103, 93-107.

STEVENSON, R. D. 1985. The relative importance of behavioral and physiological adjustments controlling body temperature in terrestrial ectotherms. Am. Nat., 126, 362-386.

WEBER, K. E. 1988. An apparatus for measurement of resistance to gas-phase agents. Drosoph. Inf. Serv., 67, 91. 
WEBER, K. E. AND DIGGINS, L. T. 1990. Increased selection response in larger populations. II. Selection for ethanol vapor resistance in Drosophila melanogaster at two population sizes. Genetics, 125, 585-597.
WHITE, E. B., DEBACH, P. AND GARBER, M. J. 1970. Artificial selection for genetic adaptation to temperature extremes in Aphytis lingnanensis Compere (Hymenoptera: Aphelinidae). Hilgardia, 40, 161-192.

\section{Appendix 1}

Maximum likelihood estimates for unimodal and bimodal distributions of $T_{\mathrm{kd}}$ at start of selection (generation 0 for Up and Control lines, generation 5 for Low lines). A significant result for the log-likelihood test suggests that a bimodal distribution provides a better explanation for the data than a unimodal distribution. $M_{\mathrm{u}}$ and $S_{\mathrm{u}}$ are the maximum likelihood estimates for mean and SD assuming a unimodal model. For the bimodal model, $P_{\text {low }}$ is the proportion of the data that fall under the lower mode, $M_{\text {low }}$ and $S_{\text {low }}$ are the mean and standard deviation of that mode, and $M_{\text {high }}$ and $S_{\text {high }}$ are the mean and standard deviation of the higher mode. The $G$ tests all have 3 d.f. (Note: the flies in Control replicate 1 in generation 0 became stuck in the column because of equipment failure, hence the abnormally high values.) Trt, treatment; Rep, replicate; Gen, generation; Con, control

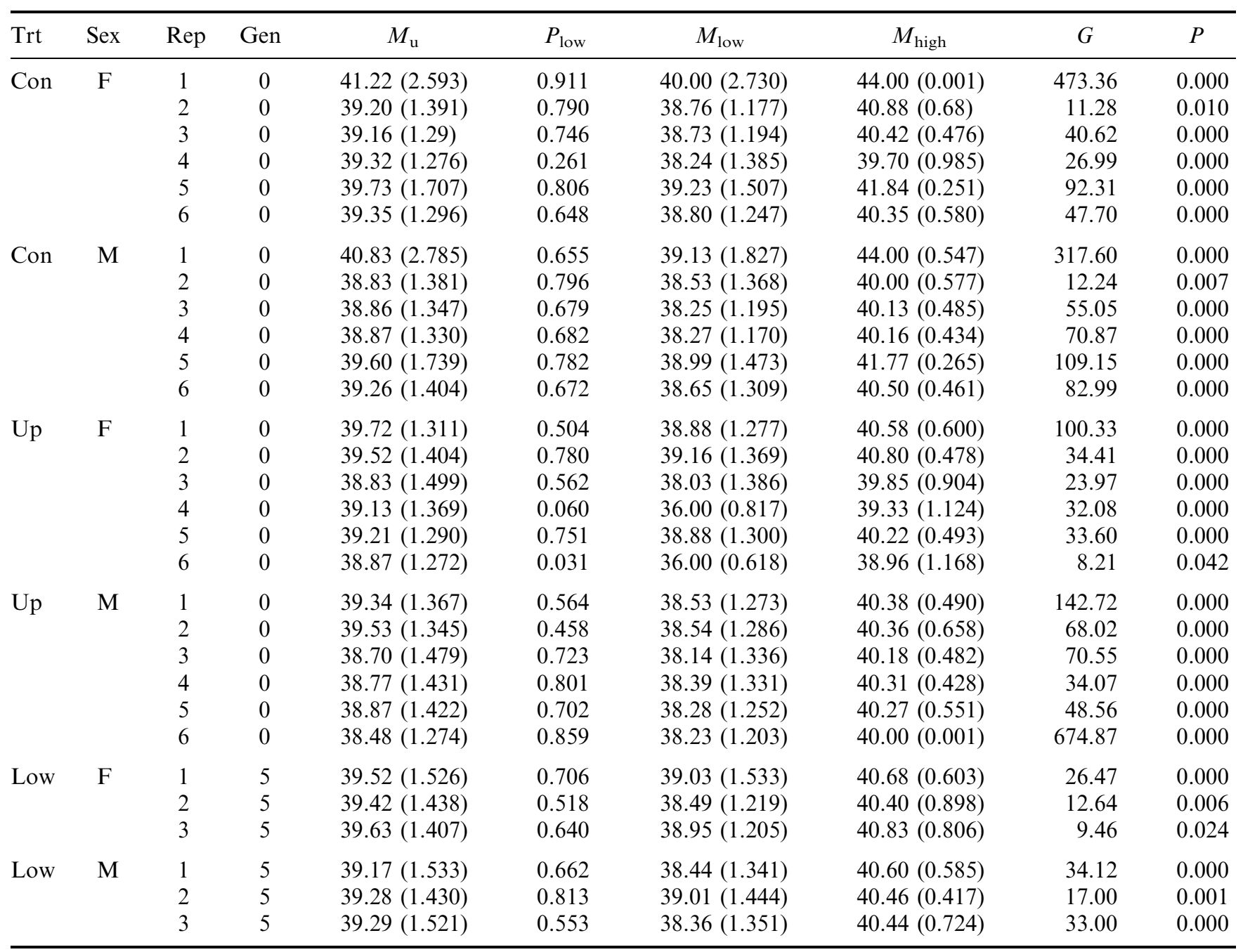




\section{Appendix 2}

Maximum likelihood estimates for unimodal and bimodal distributions of $T_{\mathrm{kd}}$ at generation 46. See Appendix 1 for details. Abbreviations as in Appendix 1

\begin{tabular}{|c|c|c|c|c|c|c|c|c|c|}
\hline Trt & Sex & Rep & Gen & $M_{\mathrm{u}}$ & $P_{\text {low }}$ & $M_{\text {low }}$ & $M_{\text {high }}$ & G & $P$ \\
\hline \multirow[t]{6}{*}{ Con } & \multirow[t]{6}{*}{$\mathrm{F}$} & 1 & 46 & $39.30(1.374)$ & 0.699 & 38.78 (1.324) & $40.50(0.390)$ & 114.14 & 0.000 \\
\hline & & 2 & 46 & $39.00(1.275)$ & 0.704 & $38.57(1.179)$ & $40.01(0.864)$ & 5.17 & 0.160 \\
\hline & & 3 & 46 & $38.85(1.533)$ & 0.812 & $38.47(1.447)$ & $40.47(0.404)$ & 52.81 & 0.000 \\
\hline & & 4 & 46 & $38.68(1.512)$ & 0.819 & $38.31(1.413)$ & $40.36(0.402)$ & 40.80 & 0.000 \\
\hline & & 5 & 46 & $38.27(1.412)$ & 0.401 & $37.33(1.393)$ & $38.91(1.018)$ & 22.66 & 0.000 \\
\hline & & 6 & 46 & 37.99 (1.434) & 0.904 & $37.78(1.341)$ & $40.00(0.001)$ & 520.87 & 0.000 \\
\hline \multirow[t]{6}{*}{ Con } & \multirow[t]{6}{*}{$\mathrm{M}$} & 1 & 46 & 39.39 (1.337) & 0.484 & 38.44 (1.314) & $40.27(0.483)$ & 168.65 & 0.000 \\
\hline & & 2 & 46 & $39.11(1.338)$ & 0.684 & $38.59(1.259)$ & $40.24(0.612)$ & 36.19 & 0.000 \\
\hline & & 3 & 46 & $39.15(1.521)$ & 0.596 & $38.31(1.427)$ & $40.37(0.443)$ & 178.10 & 0.000 \\
\hline & & 4 & 46 & $38.92(1.448)$ & 0.674 & 38.29 (1.337) & $40.23(0.447)$ & 86.91 & 0.000 \\
\hline & & 5 & 46 & $38.33(1.458)$ & 0.376 & $37.30(1.429)$ & $38.96(1.071)$ & 19.55 & 0.000 \\
\hline & & 6 & 46 & $38.30(1.560)$ & 0.743 & $37.71(1.371)$ & $40.01(0.347)$ & 113.15 & 0.000 \\
\hline \multirow[t]{6}{*}{$\mathrm{Up}$} & \multirow[t]{6}{*}{$\mathrm{F}$} & 1 & 46 & $41.79(0.562)$ & 0.017 & $40.00(1.234)$ & $41.82(0.499)$ & 73.55 & 0.000 \\
\hline & & 2 & 46 & $41.84(0.613)$ & 0.024 & $39.74(1.232)$ & $41.89(0.487)$ & 89.53 & 0.000 \\
\hline & & 3 & 46 & $41.54(0.673)$ & 0.021 & $38.67(1.430)$ & $41.60(0.494)$ & 151.66 & 0.000 \\
\hline & & 4 & 46 & $41.68(0.617)$ & 0.020 & $39.66(1.588)$ & $41.72(0.500)$ & 142.59 & 0.000 \\
\hline & & 5 & 46 & $41.55(0.677)$ & 0.022 & 39.33 (1.243) & $41.60(0.567)$ & 107.49 & 0.000 \\
\hline & & 6 & 46 & $42.00(0.656)$ & 0.033 & $39.55(1.576)$ & $42.08(0.385)$ & 317.14 & 0.000 \\
\hline \multirow[t]{6}{*}{ Up } & \multirow[t]{6}{*}{ M } & 1 & 46 & $41.71(0.697)$ & 0.054 & $39.96(1.560)$ & $41.81(0.438)$ & 248.71 & 0.000 \\
\hline & & 2 & 46 & $41.75(0.468)$ & 0.006 & $39.50(0.100)$ & $41.76(0.436)$ & 31.38 & 0.000 \\
\hline & & 3 & 46 & $41.42(0.730)$ & 0.061 & $39.50(1.331)$ & $41.55(0.441)$ & 200.35 & 0.000 \\
\hline & & 4 & 46 & $41.35(0.724)$ & 0.060 & $39.40(1.262)$ & $41.48(0.444)$ & 291.33 & 0.000 \\
\hline & & 5 & 46 & $41.51(0.716)$ & 0.027 & $38.95(1.622)$ & $41.58(0.518)$ & 202.73 & 0.000 \\
\hline & & 6 & 46 & $41.96(0.558)$ & 0.015 & $38.70(0.846)$ & $42.01(0.372)$ & 252.52 & 0.000 \\
\hline \multirow[t]{3}{*}{ Low } & \multirow[t]{3}{*}{$\mathrm{F}$} & 1 & 46 & $36.84(1.073)$ & 0.986 & $36.80(1.015)$ & $39.92(0.341)$ & 8.39 & 0.039 \\
\hline & & 2 & 46 & $37.12(1.332)$ & 1.000 & $37.12(1.332)$ & - & 0.00 & 1.000 \\
\hline & & 3 & 46 & $36.73(1.243)$ & 0.992 & $36.70(1.202)$ & $40.50(0.001)$ & 60.52 & 0.000 \\
\hline \multirow[t]{3}{*}{ Low } & \multirow[t]{3}{*}{ M } & 1 & 46 & $37.40(1.311)$ & 0.894 & $37.11(1.022)$ & $39.92(0.580)$ & 32.08 & 0.000 \\
\hline & & 2 & 46 & $37.72(1.476)$ & 0.676 & $37.00(1.007)$ & $39.22(1.133)$ & 28.25 & 0.000 \\
\hline & & 3 & 46 & 36.57 (1.319) & 0.980 & $36.50(1.222)$ & $40.21(0.324)$ & 18.70 & 0.000 \\
\hline
\end{tabular}

(C) The Genetical Society of Great Britain, Heredity, 83, 15-29. 